\title{
JUXTA-EPIPHYSIAL FRACTURE OF THE TERMINAL PHALANX OF THE FINGER
}

\author{
N. Seymour, Sheffield, England \\ From the Orthopaedic Department, Royal Infirmary, Edinburgh, Scotland
}

The purpose of this paper is to lay stress upon an injury which, although not uncommon, seems to be inadequately described. Consequently it is often improperly treated. In Bunnell (1964) there is an illustration of displaced epiphysis of the distal phalanx, but in treatment no differentiation is made from the more common open crushing injury. Watson-Jones (1956) classified the injury as one of three forms of mallet finger but described treatment appropriate to the adult types.

\section{CLINICAL AND RADIOLOGICAL FEATURES}

Figure 1 shows the typical deformity. The child or adolescent presents with a mallet finger deformity, the base of the nail lying superficial to the proximal nail fold. Figure 2 shows the radiographic appearance, the site of the fracture and the typical deformity. As in other similar fractures it is due to a weakness at the epiphysio-metaphysial junction. Rank and Wakefield (1960) noted that the deformity is due to angulation of the diaphysis on the epiphysis. They ascribed the deformity not only to the direction from which the blow is received but also to the differences in the manner of insertion of the flexor and extensor tendons into the distal phalanx. They mentioned that a lateral radiograph will differentiate between the deformity of rupture of the extensor tendon and the juxta-epiphysial fracture, but treatment of the latter was not described. Salter and Harris (1963) also indicated the importance of a lateral radiograph and stated that rupture of the extensor tendon is uncommon in childhood because the epiphysial plate is weaker than the tendon.

\section{TREATMENT}

There is a great temptation to remove the partially avulsed nail. If this is done an injury which is easily treated is converted into one which can become troublesome and can involve a long morbidity. To obtain a successful and stable reduction the nail is replaced under the proximal nail fold and a slight hyperextension force is applied to the terminal phalanx (Figs. 3 and 4). A small metal splint to hold the distal interphalangeal joint in extension is worn for two weeks. Removal of the nail tends to make reduction unstable. Internal fixation by Kirschner wires is unnecessary and may lead to complications.

In a small series of twenty cases several illustrated the difficulties and disadvantages of other forms of treatment.

Kirschner wire fixation was carried out in five cases. A single longitudinal wire or two crossed wires were used to fix the shaft to the epiphysis after reduction of the fracture. Adequate reduction and fixation were obtained in all cases. In one case osteomyelitis of the terminal phalanx eventually led to amputation of the finger. In two cases infection in the wire track was present for several weeks. Although Kirschner wiring is often indicated in the treatment of some phalangeal fractures, the incidence of complications and the success of conservative treatment make its use unjustified and unnecessary in juxta-epiphysial fractures. 
In six cases the nail was removed before manipulation. Although reduction was obtained in all, the position could not be held at the time of reduction in one and Kirschner wire fixation was adopted. In three of the remaining five some slip at the fracture site occurred within a few days of reduction. In two of these cases the deformity was accepted. Six weeks later

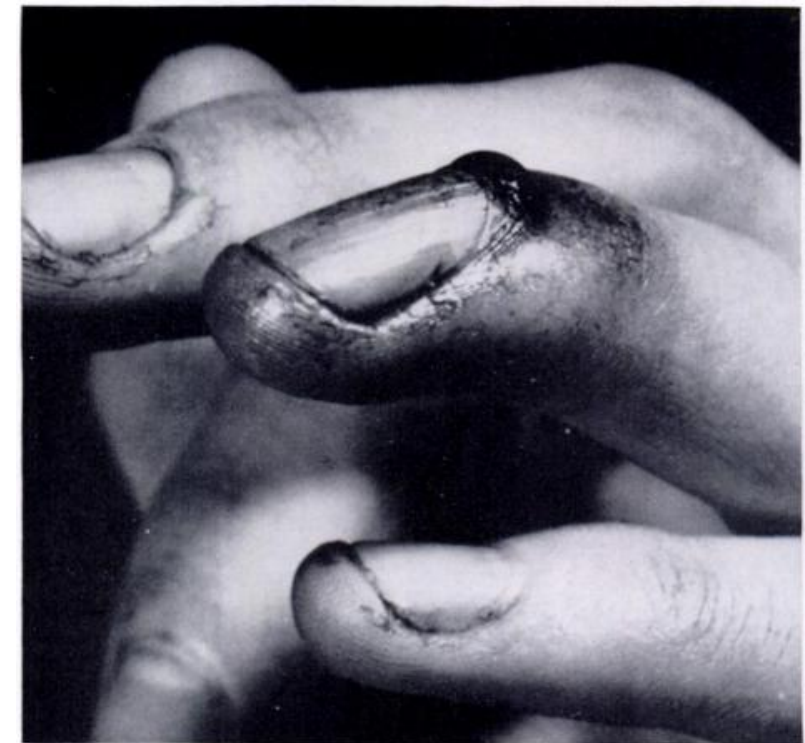

FIG. 1

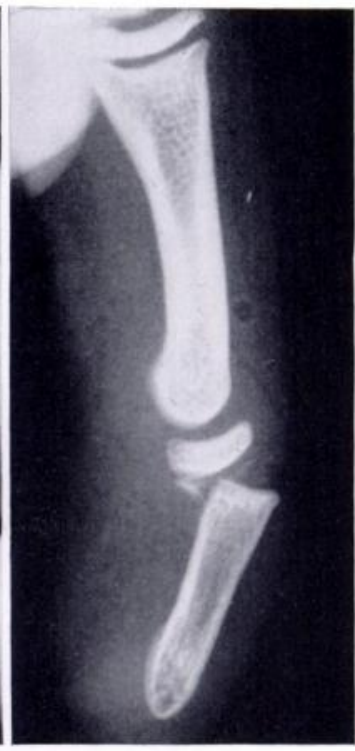

FIG. 2

Figure 1-The typical deformity. Figure 2-Radiograph showing angulation of the phalanx distal to the epiphysis.

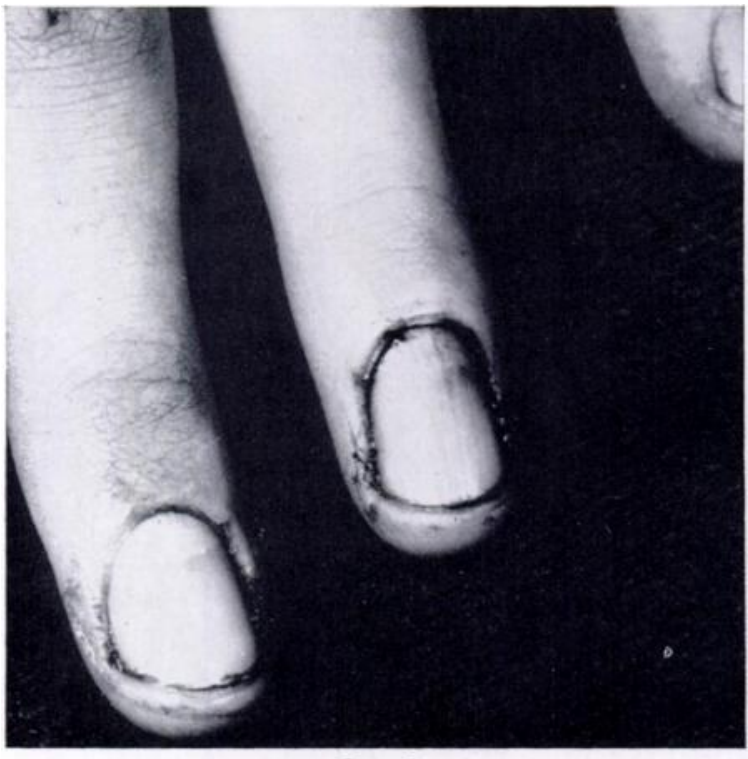

FIG. 3

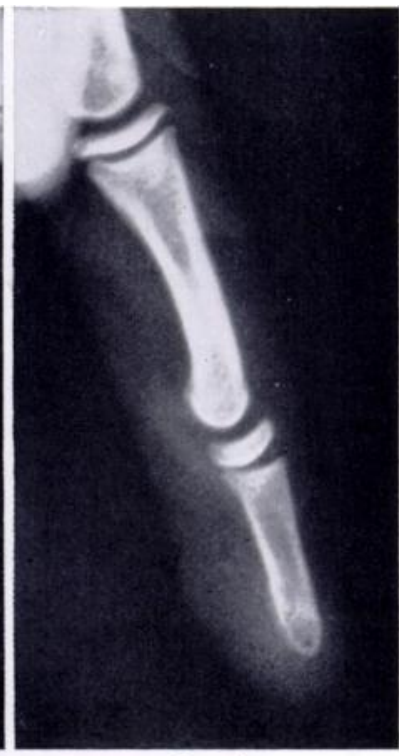

FIG. 4

Figure 3-Appearance of finger after reduction. Figure 4-Radiograph after reduction of the fracture.

each had a forward angulation deformity of 20 degrees at the epiphysis; in the next six months this improved in each case to about 10 degrees. In one case in this group the slip was not acceptable as it was almost complete; Kirschner wire fixation was used with a satisfactory 
result. Three of these patients whose nail had been removed developed some infection in the nail bed necessitating frequent hospital attendance for dressings.

All the patients treated by replacement of the nail, manipulation and splinting did well. An acceptable reduction was always obtained and there was no case of early or late redisplacement. All the patients had normal or near-normal function at the distal interphalangeal joint four to five weeks after the injury.

\section{SUMMARY}

The treatment of juxta-epiphysial fractures of the terminal phalanx is discussed. It is submitted that a simple form of conservative treatment gives the best results.

I should like to thank Professor J. I. P. James and Mr J. Chalmers for their advice and encouragement.

\section{REFERENCES}

Bunnelt, S. (1964): Surgery of the Hand. Fourth edition, p. 654. Montreal and Philadelphia: J. B. Lippincott Company.

Rank, B. K., and Wakefield, A. R. (1960): Surgery of Repair as Applied to Hand Injuries. Second edition, p. 116. Edinburgh and London: E. \& S. Livingstone Ltd.

Salter, R. B., and Harris, W. R. (1963): Injuries Involving the Epiphyseal Plate. Journal of Bone and Joint Surgery, 45-A, 587.

Watson-Jones, Sir R. (1956): Fractures and Joint Injuries. Fourth edition, Volume 2. Edinburgh and London: E. \& S. Livingstone Ltd.

vol. 48 B, NO. 2, MAY 1966 